\title{
Needs and Supports of People with Intellectual Disability and Their Families in Catalonia
}

Rosa Vilaseca*, Marta Gràcia*, Francesc S. Beltran*, Mariona Dalmau ${ }^{\dagger}$, Elisabeth Alomar ${ }^{\dagger}$, Ana Luisa Adam-Alcocer ${ }^{\dagger}$ and David Simó-Pinatella ${ }^{\dagger}$

*Department of Developmental and Educational Psychology, University of Barcelona, Barcelona, Spain; ${ }^{\dagger}$ Ramon LLull University, Barcelona, Spain

Accepted for publication 26 June 2015

Background The study assesses the support needs of individuals with intellectual disability and their families in Catalonia. The present authors examine family quality of life (FQoL), identify the individual services required and assess families' perceptions of the extent to which their family member with intellectual disability and they themselves receive the services they need.

Materials and Methods The N\&S questionnaire (Needs and Supports for people with intellectual disability and their families) was administered to 2160 families with a family member with intellectual disability aged under 70 in Catalonia (Spain).

Results Overall mean FQoL was quite high. FQoL was associated with family income, education, employment and percentage level of disability. Neither people with intellectual disability nor their families receive the specific support they need.

Conclusions Besides providing specific support for individuals with intellectual disability, local policymakers and practitioners should apply a familycentred approach to the provision of support for families in order to improve FQoL.

Keywords: families' needs, family quality of Life, family support, needs of people with intellectual disability, support for people with intellectual disability

\section{Introduction}

Recent research on family quality of life (FQoL) has striven to ascertain what aspects of family life contribute most to quality of life (QoL), and consequently to identify the aspects which, once improved, may enhance QoL for families of people with intellectual disability (Brown et al. 2006a,b; Zuna et al. 2009). FQoL is defined as 'a dynamic sense of well-being of the family, collectively and subjectively defined and informed by its members, in which individual and family-level needs interact' (Zuna et al. 2010, p. 262). This definition recognizes the family as the main context of development and acknowledges the importance of FQoL for improving families' ability to cope with their family member with intellectual disability and for assessing the possible positive impact of support or services. This model recognizes two key needs: the need for support for the individual with intellectual disability and the need for support for the family. For this reason, it is important to determine the needs of the family and of the individual with disabilities and to ascertain whether family members themselves believe these needs are met or unmet. This study aimed to identify the support needs of individuals with intellectual disability and their families in Catalonia, an autonomous region in the north-east of the Iberian Peninsula. Various scales have been developed in different countries to assess FQoL, of which three stand out. The first is the Beach Centre on Disability's Family Quality of Life Scale, which has mainly been used with the families of young people with intellectual and developmental disabilities (Hoffman et al. 2006; Turnbull et al. 2007). The second, the Family Quality of Life Survey (Brown et al. 2006a,b, 2011; Kober 2010), was developed by an international group of researchers in Canada, the United States, Israel and Australia and has been used in families with members of different ages and various types of intellectual 
disability. Finally, the Spanish Family Quality of Life Scales (CdVF-E) were constructed to measure QoL in families with a family member with intellectual disability (Giné et al. 2013); one of the scales was designed for children and teenagers up to 18 years old, and the other was designed for adults over 18 .

The focus on support for individuals with disabilities has been extensively explored, especially following the change in perspective adopted by the American Association on Intellectual and Developmental Disabilities (AAMR 1992, AAMR 2002; AAIDD 2010) away from the traditional deficit-within-the-person model to the supports model. Before the 1992 definition of mental retardation, the family's needs revolved primarily around the person with intellectual disability and focused more on the deficit presented by person in question than on the planning and provision of supports. Since 1992 (AAMR, Luckasson et al. 1992), rather than as something static and immutable, intellectual disability has been seen as a condition that might improve with the provision of support. The new conception considers the social and environmental factors that may affect families with a person with disabilities. So, in this conception a prominent role is given to supports for all members of the family included the person with intellectual disability. The definition stresses the need to provide supports when there is a mismatch between the person's individual capacity and environmental demands. For example, when the person with intellectual disability is unable to follow the school curriculum, an individualized support plan is set up, or when the person with intellectual disability is unable to follow instructions and cannot work autonomously, the written instructions are adapted with the aid of 'easy-to-read' text. Supports are defined as 'resources and strategies that aim to promote the development, education, interests and personal wellbeing of a person and that enhance individual functioning' (Luckasson et al. 2002; Schalock et al. 2010). Consequently, researchers and practitioners are keen to explore supports for individuals with disabilities. With their support needs identified and the individualized support plans implemented, people with intellectual disability will be able to function successfully and their personal results will improve (Luckasson \& Schalock 2013). Recently, a number of instruments for assessing QoL in people with intellectual disability have been developed and validated in our environment. Examples are the GENCAT Scale (Verdugo et al. 2009, 2010a,b; Gómez et al. 2010, 2011), the INICO-FEAPS Scale (Verdugo et al. 2013; Gómez et al. 2015), the Integral
Scale (Verdugo et al. 2010a,b), the San Martin Scale (Verdugo et al. 2014) and the POS Scale (Van Loon et al. 2009; Carbó-Carreté et al. 2015). The use of these instruments has made it possible to objectively assess the QoL in people with intellectual disability and also to evaluate the intervention programmes designed to improve their personal results.

While this is a step forward, the provision of individual supports is not in itself enough; it is also necessary to provide resources and supports for families with a family member with intellectual disability throughout their life cycle, as it is the parents who face the greatest challenge (Turnbull et al. 2006). Indeed, families are the principal caregivers of both children and adults with disabilities and play an important role in their well-being (Turnbull \& Turnbull 1990; Dunst \& Deal 1994; Carpenter 1997).

The stressors faced by families supporting a family member with intellectual disability are well known (Hastings 2003; Plant \& Sanders 2007). Parental distress and family functioning impact family member with intellectual disability in numerous ways, affecting their cognitive, behavioural and social development. It is now recognized that families with a family member with disabilities need support for the entire family unit, defined as a set of support strategies aimed to promote the emotional and material well-being of all family members and the development of the person with disabilities (Kyzar et al. 2012). The absence of this support will have repercussions for the QoL of both the family member with disabilities and the family unit as a whole (Dunst \& Trivette 2009; Zuna et al. 2010).

National and local programmes in each country offer services targeted mainly at people with disabilities and, to a lesser extent, at their families. But what are the needs of families with a family member with intellectual disability, and what are the needs of individuals with intellectual disability themselves? Are these needs adequately met throughout the different stages of development? If the different organizations involved (health centres, schools, regulatory bodies, etc.) are to meet these needs, then it is first necessary to establish the needs of families and individuals with intellectual disability and to identify the factors that influence them. Gathering the views of families themselves regarding their needs and those of their family members with intellectual disability, and ascertaining to what extent the support they receive is sufficient, will help to identify the kind of services required to promote a better FQoL (Brown et al. 2012). It is essential to explore the specific needs of families and how these needs can 
be addressed by community agencies (Brown et al. 2003).

International research indicates high levels of unmet needs among parents of people with disabilities when seeking services for both their family member and the family (Baldwin \& Carlisle 1994; Sloper 1999). Even today, many parents perceive that their needs continue to be unmet and are less likely to be met than are those of their family member with intellectual disability (Beresford 1995; Eskow et al. 2011). These needs include, for example, support to enable parents to combine their working lives with looking after the person with intellectual disability, and support to enable them to enjoy life as a couple and make the most of leisure time by leaving the family member with intellectual disability at home with a specialist carer.

In Catalonia, family support services remain relatively thin on the ground. In 2006, the Intellectual Disability Association of Catalonia (Discapacitat Intellectual Catalunya, Intellectual Disability Catalonia, DINCAT) published a guide to resources and services for families (APPS 2006). However, although this guide is designed for families, the majority of services and resources listed focus more on the individual with disabilities; the list ranges from services and resources focused on the early stages of life, such as early intervention centres, to services for adults with intellectual disability such as occupational therapy centres, special employment centres and residential care homes. The guide is undoubtedly useful, but it centres specifically on the aid available for the person with intellectual disability and includes little help for other family members (parents, siblings and so on) who may also be in need of attention. The website of the Catalan regional government (the Generalitat: www20.gencat) lists services targeted at individuals with intellectual disability and at families in general, but there are no resources designed specifically for other family members at various developmental stages. Most of these services apply a person-centred approach as described by Giné et al. (2011). In that study, the authors outline the procedure used to define the items in the questionnaire the present authors present here.

This study aimed to identify the support needs of individuals with intellectual disability and their families in Catalonia. The specific goals are (i) to examine QoL in families with a family member with intellectual disability; (ii) to examine the relationship between demographic variables and FQoL; (iii) to examine the individual services needed and to determine families' perceptions of how far their family member with intellectual disability receives the services they need; and (iv) to examine the family services needed and to determine how far families of individuals with intellectual disability receive the services they need.

\section{Materials and Methods}

\section{Participants}

A sample of families in which at least one member has intellectual disability was recruited through various services in Catalonia (early intervention centres, special education schools, occupational therapy centres, special employment centres and residential care homes), all of them affiliated to DINCAT and FEAPS (Confederación Española de Organizaciones en favor de las Personas con Discapacidad Intelectual, the Spanish Confederation of Organizations in favour of People with Intellectual Disability). A total of 2160 families resident in Catalonia with a family member with intellectual disability participated in the study. There were no restrictions with regard to the person's age or level of intellectual disability.

The majority of participants $(77.36 \%)$ were parents, and $19.31 \%$ of respondents were siblings or other family members. As regards gender, $53.01 \%$ were female and $28.98 \%$ male and their ages ranged between 17 and 74 $(M=51.20, \quad \mathrm{SD}=11.4)$. Most of the respondents $(69.35 \%)$ had completed compulsory education, $19.03 \%$ had been to university, and $8.24 \%$ had had no formal education. Many of the respondents were working full time $(31.94 \%)$, while others were working part-time $(9.31 \%)$, retired $(27.18 \%)$, unemployed $(6.02 \%)$ or homemakers $(18.01 \%)$. Regarding their area of residence, the majority lived in a city $(57.36 \%)$, semi-urban areas $(24.54 \%)$ or rural areas $(12.08 \%)$. Finally, with regard to family income $28.19 \%$ earned less than $€ 1200$ per month, the majority (48.94\%) earned between $€ 1200$ and $€ 2500$ per month, and just $17.31 \%$ earned over $€ 2500$ per month $(M=1.327 .40 ; \mathrm{SD}=338.60)$.

As far as the characteristics of the individuals with intellectual disability are concerned, there was a higher percentage of males $(57.27 \%)$ than females $(40.56 \%)$, and their ages ranged from 2 to 70 years $(M=33.20$; $\mathrm{SD}=13.30)$. Most of them $(81.62 \%)$ lived in the family home, and $12.78 \%$ were in residential care. As regards the level of intellectual disability (according to the classification used by the Spanish Ministry of Health and Social Affairs), 19.72\% had a mild disability, 33.29\% moderate and $41.53 \%$ severe. 


\section{Measures}

Two measures were used: (i) a brief demographic questionnaire and (ii) the Needs and Supports for People with Intellectual Disability and Their Families questionnaire (N\&S questionnaire) developed ad hoc for this study. As none of the scales mentioned in the introduction provided the information the present authors needed to meet our objectives, the present authors decided to create our own questionnaire. In this study, the present authors needed to use an instrument that took into account the specific cultural, social and economic features of Catalonia, the region where the data were to be collected. Our main aim was to determine the QoL in these families and their support needs, in order to be able to review the support currently provided by government institutions.

The N\&S questionnaire has two parts. The first part explores the family's degree of agreement with 111 items grouped and labelled under 13 FQoL domains identified previously in other studies (Brown et al. 2006a,b; Hoffman et al. 2006; Giné et al. 2013): access to information (eight items; e.g. 'The present authors receive sufficient information on the services and supports available'), emotional well-being (nine items; e.g. 'the present authors feel safe and relaxed at home'), family relationships (eight items; e.g. 'having a family member with intellectual disability has improved my relationship with my partner'), health (six items; e.g., 'Caring for a family member with intellectual disability has triggered mental health problems in one or more of the members of the family'), family-professional partnership (nine items; e.g. 'the present authors feel respected and valued by the practitioners attending our family member with intellectual disability'), financial well-being (six items; e.g. 'Caring for a family member with intellectual disability requires extra financial outlay to pay for medication and nappies'), disability-related supports (13 items; e.g. 'government spending on disability (research, prevention, etc.) is appropriate for a developed country such as ours'), family support (eight items; e.g. 'The present authors consider that the siblings of the family member with intellectual disability receive the aid and support they need'), support for the individual with intellectual disability (nine items; e.g. 'The present authors consider that the family member with receives the aid and support he/she needs'), accommodation to family needs (nine items; e.g. 'My employers help me to make my hours of work compatible with caring for the needs of my family member with intellectual disability'), parents' organization and skills (11 items; e.g. 'at home the present authors find it difficult to talk about sex education with our family member with intellectual disability'), social inclusion and participation [eight items; e.g. 'The family member with intellectual disability often takes part in activities/groups in our area (sports clubs, theatre groups, music, etc.)'] and values (seven items; e.g. 'Having a family member with intellectual disability has helped us to value positive aspects of our life'). Parents were asked to rate their degree of agreement with each of the 111 items on a Likert scale ranging from 1 (strongly disagree) to 5 (strongly agree). There was also a 'not applicable' option. The total score on the first part of this questionnaire corresponds to the sum of the scores obtained on the 13 FQoL domains.

The items that comprised the questionnaire were assessed by a panel of experts who evaluated them in accordance with the following parameters: ease of understanding, possible lack of relevant aspects and time needed to respond. The experts' opinions were analysed by the research group and incorporated into the questionnaire, which was then sent to the 30 families with a family member with intellectual disability. Families were also asked to answer questions about the format and structure of the questionnaire. A Pearson correlation between the items and the total of the test showed a discrimination index above the 0.30 for all items. This confirmed the appropriateness of the questionnaire items, and the suggestions proposed in the answers regarding the format and structure were incorporated into the questionnaire. The final version of the N\&S questionnaire was then administered to the study sample.

The second part of the questionnaire explores the services and supports that the individual with intellectual disability and his/her family need and receive. It comprises two different sections: (i) one indicating the supports that the member with intellectual disability needs and receives (28 options) and (ii) another indicating the services that the family needs and receives (13 options).

The sections referring to services and supports for families and individuals with intellectual disability centre on support received in the past 6 months. Interviewees were first asked whether or not they need certain services/supports [e.g., 'which of the following supports or services does your family member with intellectual disability need?/which of the following supports or services does your family need?' (Families complete a checklist answering yes/no)]. If they answer 
affirmatively, they report the extent to which they receive the services/supports (e.g. 'if he/she/your family needs support, to what extent does your family member with intellectual disability /does your family receive it?' Families answer: 'not at all', 'slightly', 'to an adequate extent'). The services and supports that the family member with intellectual disability needs and receives were categorized under the following headings: health care, transport and mobility, communication, sensory disability, education, psychological care, guidance and support for the transition to adult life, leisure time, coordination of services, adaptation of the home, and medication and/or nappy changes. The present authors also included the option 'Other' so that families could describe supports that their family member with intellectual disability receives but did not feature among the options listed.

The services and supports that families need and receive are categorized under the following headings: respite care and assistance, information and guidance, financial assistance, household support and adaptations to family transport. As before, respondents may choose the option 'Other' if needed.

The total N\&S questionnaire score yielded a Cronbach's alpha of 0.85 and ranged between 0.76 and 0.97 for the 13 domains. In addition, the reliability according to the split-half method, with application of the Spearman-Brown correction, provided a reliability of 0.97 for the total and values between 0.75 and 0.91 for the 13 dimensions (See Table 1).

\section{Procedure}

Ethical approval was obtained from the Ethics Committee of the Network of Ethics Committees in Universities and Public Research Centres in Spain. Participants were recruited through associations of parents of individuals with intellectual disability, all affiliated to DINCAT and FEAPS. The coordinators of these associations were contacted by telephone or mail by the lead researcher and informed of the purpose of the study and requirements for participation. If an association decided to participate, its coordinator contacted the families and described the study to them. Families who agreed to participate were given a research pack including an informed consent form (in accordance with the ethical guidelines of the Spanish Psychological Society), an information sheet, a brief demographic questionnaire, a copy of the N\&S questionnaire and an envelope in which to return the completed questionnaires to their coordinator. Once the coordinator had collected all the completed
Table I Descriptive data for the N\&S questionnaire (Part I) (mean and SD, minimum and maximum scores, Cronbach's alpha and reliability according to the split-half method by domain)

\begin{tabular}{|c|c|c|c|c|c|c|}
\hline Domain & $M$ & $S D$ & Minimum & Maximum & $\alpha$ & $\begin{array}{l}\text { Reliability } \\
\text { split-half method }\end{array}$ \\
\hline Access to information & 2.76 & 1.21 & 13 & 40 & 0.87 & 0.87 \\
\hline Emotional well-being & 3.11 & 1.40 & 16 & 41 & 0.77 & 0.84 \\
\hline Family relationships & 3.52 & 1.44 & 14 & 40 & 0.81 & 0.75 \\
\hline Health & 3.69 & 1.44 & 10 & 30 & 0.85 & 0.87 \\
\hline $\begin{array}{l}\text { Family-professional } \\
\text { partnership }\end{array}$ & 3.73 & 1.15 & 19 & 45 & 0.93 & 0.90 \\
\hline Financial well-being & 2.76 & 1.45 & 6 & 30 & 0.78 & 0.63 \\
\hline Disability-related supports & 2.10 & 1.08 & 14 & 65 & 0.88 & 0.84 \\
\hline Family support & 2.42 & 1.23 & 8 & 37 & 0.76 & 0.76 \\
\hline $\begin{array}{l}\text { Support for the individual } \\
\text { with intellectual } \\
\text { disability }\end{array}$ & 2.97 & 1.25 & 13 & 45 & 0.80 & 0.81 \\
\hline $\begin{array}{l}\text { Accommodation to } \\
\text { family needs }\end{array}$ & 3.10 & 1.35 & 12 & 45 & 0.83 & 0.85 \\
\hline $\begin{array}{l}\text { Parents' organization } \\
\text { and skills }\end{array}$ & 3.08 & 1.35 & 19 & 55 & 0.83 & 0.79 \\
\hline $\begin{array}{l}\text { Social inclusion and } \\
\text { participation }\end{array}$ & 2.99 & 1.35 & 13 & 40 & 0.80 & 0.82 \\
\hline Values & 3.63 & 1.18 & 7 & 35 & 0.97 & 0.91 \\
\hline Total & 3.07 & 1.64 & 164 & 548 & 0.85 & 0.97 \\
\hline
\end{tabular}


questionnaires from all the participants, these were sent by post to the lead researcher. The families were informed that they could raise any queries with the lead researcher at any time during the process. A total of 15000 questionnaires were sent out, and the final response rate was $14.40 \%$. All of the research packs were returned to the lead researcher within 8 weeks.

\section{Results}

In connection with the first of our objectives, Table 1 shows the overall descriptive statistics of FQoL for the families that completed the N\&S questionnaire (Part I).

The overall mean FQoL was quite high $((M=3.07$, $\mathrm{SD}=1.64)$. The family-professional partnership domain scored highest $(M=3.73, \mathrm{SD}=1.15)$, followed by health $(M=3.69, \mathrm{SD}=1.44)$ and values $(M=3.63, \mathrm{SD}=1.18)$. Disability-related supports $(M=2.10 ; \mathrm{SD}=1.08)$ and family support $(M=2.42, \mathrm{SD}=1.23)$ had the lowest mean values.

In relation to our second objective, that is to examine the relation between the demographic variables and the FQoL, one-way ANOva for each variable showed that the scores on the family questionnaire depended on the educational level $\left(F_{2,2065}=22.10, P<0.001, \eta^{2}=0.13\right)$, employment status $\left(F_{6,2039}=4.96, P=0.009, \eta^{2}=0.11\right)$ and family income $\left(F_{2,2019}=29.87, P<0.001, \eta^{2}=0.13\right)$. Post hoc comparisons showed $(P<0.001$ in all cases) that the higher the educational level, the higher the FQoL $\left(M_{\text {without studies }}=258.33, \mathrm{SD}_{\text {without }}\right.$ studies $=82.50$; $M_{\text {elementary studies }}=279.10, \mathrm{SD}_{\text {elementary studies }}=68.48$; and $M_{\text {university }}=297.42, \mathrm{SD}_{\text {university }}=60.16$ ). Quality of life was also higher in families in which the respondent was in full-time employment than in the cases in which he/ she did not work $\left(M_{\text {full-time work }}=271.35, \mathrm{SD}_{\text {full-time }}\right.$ work $=78.16$ versus $M_{\text {unemployed }}=284.30, \mathrm{SD}_{\text {unemployed }}=$ 61.23). Finally, the analyses show that higher incomes were also associated with higher FQoL $\left(M_{-<1200}=268.67, \mathrm{SD}_{-<1200}=73.49 ; M_{1200-2500}=282.45\right.$, $\mathrm{SD}_{1200-2500}=65.82 ; \quad$ and $\quad M_{>2500}=302.45, \quad \mathrm{SD}_{>2500}=$ 58.08).

The results also indicate a relationship between FQoL and the percentage level of disability $\left(F_{3,2018}=4.96\right.$, $\left.P=0.007, \eta^{2}=0.05\right)$. A post hoc analysis showed a higher FQoL among individuals with more disability than in their less disabled peers $\left(M_{\text {severe }}\right.$ disability $=284.30, \mathrm{SD}_{\text {severe }}$ disability $=61.23$ versus $M_{\text {mild }}$ disability $=271.35, \mathrm{SD}_{\text {mild disability }}=78.16 ; P<0.01$ ). With respect to the services and support needed and received, the results are divided into two groups. The first refers to the study's third objective, namely to explore the individual services needed and to examine the degree to which the family member with intellectual disability receives the services he/she needs. The results are grouped into 28 areas of support (reflecting the organization of the services in Catalonia) and show the number of individuals who reported no needs, the number of individuals who reported needs and the percentage of people with intellectual disability who receive either sufficient or insufficient support (Table 2). The second group is related to the fourth study objective, that is to explore the family services needed and to examine the degree to which families receive the services they need. In this case, the supports are grouped into 13 areas, once again reflecting the organization of services in Catalonia and arranged in the same way as in the previous table (Table 3).

Table 2 shows that the top five individual services needed are specialized healthcare services $(n=1299)$, leisure services $(n=1224)$, personal assistance $(n=1051)$, general healthcare services $(n=993)$ and psychological support $(n=920)$. Table 2 also provides the details of the other 23 individual services that families perceive as necessary. A large number of families perceive that their family member with ID does not need support in particular areas, due probably to the characteristics of his/her disability, (for example technical assistance for auditory disability $(n=1643)$, mobility services $(n=1519)$ or psychomotor activity services $(n=1145)$, or because of their age (e.g., in adapted nursery school ( $n=1619)$ or guidance on transition to the working world $(n=1249))$, or because of the state of health, (e.g. hospital admission services $(n=1346)$ or mental health services $(n=1080))$, among others. With regard to whether families perceive that their family member with intellectual disability receives the supports he/she needs, Table 2 shows that service provision for individuals with intellectual disability remains insufficient in many areas, even though in other areas families are satisfied with the support provided. The top five areas in which families believe their family member with intellectual disability does not receive enough support are in relation to help adapting the home $(78.89 \%)$, speech and language services (78.74\%), alternative and augmentative communication systems $(77.32 \%)$, lifelong training services $(73.17 \%)$ and technical assistance for sensorial disabilities (visual: $71.48 \%$ and auditory: $71.05 \%$ ). There is a series of services that families situate in an intermediate position, as they report that the provision is insufficient in between 50 and $69 \%$ of cases, although the present authors should also stress that between 30 and $46 \%$ of these people receive sufficient support (e.g. in relation to 
Table 2 Services and supports that the individual with intellectual disability needs and receives

\begin{tabular}{|c|c|c|c|c|}
\hline Services and supports & $\begin{array}{l}\text { No needs (number } \\
\text { of individuals) }\end{array}$ & $\begin{array}{l}\text { Needs (number } \\
\text { of individuals) }\end{array}$ & $\begin{array}{l}\text { Receives but } \\
\text { insufficiently (\%) }\end{array}$ & Receives sufficient (\%) \\
\hline Specialized healthcare services & 646 & 1299 & 44.01 & 55.99 \\
\hline General healthcare services & 930 & 993 & 37.92 & 62.08 \\
\hline Mental health services & 1080 & 812 & 50.61 & 49.39 \\
\hline Hospital admission services & 1346 & 496 & 45.10 & 54.90 \\
\hline Physical therapy & 1216 & 646 & 68.73 & 31.27 \\
\hline Psychomotor activity services & 1145 & 702 & 68.31 & 31.69 \\
\hline Transportation & 1361 & 498 & 48.86 & 51.14 \\
\hline Personal assistance & 834 & 1051 & 53.76 & 46.24 \\
\hline Mobility services & 1519 & 341 & 53.66 & 46.34 \\
\hline At-home care & 1255 & 633 & 66.86 & 33.14 \\
\hline Speech and/or language services & 1120 & 732 & 78.74 & 21.26 \\
\hline $\begin{array}{l}\text { Alternative and augmentative } \\
\text { communication systems }\end{array}$ & 1206 & 605 & 77.32 & 22.68 \\
\hline Technical assistance for visual disability & 1482 & 366 & 71.48 & 28.52 \\
\hline Technical assistance for auditory disability & 1643 & 185 & 71.05 & 28.95 \\
\hline Adapted nursery school & 1619 & 128 & 69.57 & 30.43 \\
\hline Inclusive school & 1475 & 195 & 66.89 & 33.11 \\
\hline Specialized educational services & 975 & 788 & 42.70 & 57.30 \\
\hline Psychological support & 877 & 920 & 64.31 & 35.69 \\
\hline Behavioural support & 1078 & 713 & 69.30 & 30.70 \\
\hline Guidance on transition to the working world & 1249 & 480 & 63.22 & 36.78 \\
\hline Guidance for inclusive education & 1145 & 590 & 69.28 & 30.72 \\
\hline $\begin{array}{l}\text { Support service for professional } \\
\text { development at a special work centre }\end{array}$ & 973 & 811 & 47.16 & 52.84 \\
\hline $\begin{array}{l}\text { Support service for professional } \\
\text { development in an ordinary company }\end{array}$ & 1315 & 390 & 61.81 & 38.19 \\
\hline Leisure services & 619 & 1224 & 67.07 & 32.93 \\
\hline Lifelong learning service & 842 & 899 & 73.17 & 26.83 \\
\hline Service coordination & 901 & 812 & 63.46 & 36.54 \\
\hline Support to adapt the home & 1261 & 519 & 78.89 & 21.11 \\
\hline Support for medication and/or nappies & 1124 & 631 & 54 & 46 \\
\hline
\end{tabular}

help and guidance at inclusive school (66.89\%), homecare $(66.86 \%)$, aid for behavioural disorders (69.30\%), psychological support $(64.31 \%)$, physical therapy $(68.73 \%)$, psychomotor activity services $(68.31 \%)$, service coordination $(63.46 \%)$, and guidance concerning their participation in educational activities (69.28\%), work activities $(63.22 \%)$ and leisure services $(67.07 \%))$. The top five areas in which families believe that their family member with intellectual disability receives sufficient support are general healthcare services (62.08\%), specialized educational services $(57.30 \%)$, specialized healthcare services (55.99\%), hospital admission services $(54.90 \%)$ and support service for professional development at a special work centre (52.84\%).

Table 3 shows the same kind of results as Table 2, but in this case centred on the families. The present authors see that the top five family services needed are information about legal rights $(n=1385)$, information about where to get services for the family member ( $n=1372)$, information about where to get services for the family $(n=1271)$, information about planning for the future $(n=1268)$ and money to help pay bills $(n=1082)$. Table 3 also provides the details of the other eight family services needed.

With regard to whether the families receive the services they need, our results show that this is not the case in a very high percentage of families. The most obvious disparities between what families need and what they receive concern the areas of household support for caring for the family member with intellectual disability $(84.78 \%)$, money to help pay bills $(83.07 \%)$ and information about planning for the future 
Table 3 Services and supports that the family needs and receives

\begin{tabular}{|c|c|c|c|c|}
\hline Services and Supports & $\begin{array}{l}\text { No needs (number } \\
\text { of families) }\end{array}$ & $\begin{array}{l}\text { Needs (number } \\
\text { of families) }\end{array}$ & $\begin{array}{l}\text { Receives } \\
\text { insufficiently (\%) }\end{array}$ & $\begin{array}{l}\text { Receives } \\
\text { sufficient (\%) }\end{array}$ \\
\hline Respite care & 1074 & 789 & 78.02 & 21.98 \\
\hline Parenting or family training & 1057 & 758 & 70.46 & 29.54 \\
\hline Support groups to siblings & 1000 & 809 & 68.55 & 31.45 \\
\hline Counselling & 775 & 1046 & 74.24 & 25.76 \\
\hline Information about specific disabilities & 962 & 806 & 79.79 & 20.21 \\
\hline Information about where to get services for your child & 475 & 1372 & 75.33 & 24.67 \\
\hline Information about where to get services for your family & 572 & 1271 & 78.69 & 21.31 \\
\hline Information about legal rights & 472 & 1385 & 77.61 & 22.39 \\
\hline Information about planning for the future & 571 & 1268 & 80.21 & 19.79 \\
\hline Information about transition services & 1151 & 559 & 77.38 & 22.62 \\
\hline Money to help pay bills & 753 & 1082 & 83.07 & 16.93 \\
\hline Household support & 1113 & 709 & 84.78 & 15.22 \\
\hline Adaptations to family transportation & 1429 & 373 & 77.78 & 22.22 \\
\hline
\end{tabular}

(80.21\%). Insufficiencies are also evident in the areas of parenting or family training $(70.46 \%)$, respite care (78.02\%), information about services available for the family member with intellectual disability (75.33\%), and, especially, information regarding services for specific disabilities (79.79\%) and for the family itself (78.69\%). The provision of support groups to siblings was also considered insufficient, though to a lesser extent $(68.55 \%)$. It is also clear that the areas in which the percentage of families who reported received sufficient support is higher, though never their percentage is higher than $32 \%$.

\section{Discussion}

With regard to the first objective, namely to examine the QoL in families with a family member with intellectual disability, the overall mean FQoL was quite high; it was in line with other studies of FQoL conducted both in Catalonia (Giné et al. in press) and in other countries (Hoffman et al. 2006; Turnbull et al. 2007; Kober 2010; Brown et al. 2011). However, it should be borne in mind that our figures are averages derived from 2.160 families, some of which had very low FQoL scores and were in dire need of support. This serves as a reminder that if the present authors really wish to improve the QoL in families with a family member with intellectual disability, the present authors must explore and respond to the individual needs of each family, especially those with the greatest need for support (Brown et al. 2003).

In terms of the different dimensions of FQoL, the highest score corresponds to the 'family-professional partnership'. This confirms that the partnership with professionals is one of the aspects most directly related to FQoL (Turnbull et al. 2006; Balcells-Balcells et al. 2011). The domains of health, values, family relationships, and social inclusion and participation also earned fairly high scores, while the lowest scores were those for disability-related support and family support. These results are in line with those reported in other studies of FQoL, which reveal families' discontent with the services for both the family as a whole and their family member with intellectual disability (Hoffman et al. 2006; Turnbull et al. 2007; Kober 2010; Brown et al. 2011; Giné et al. in press). The findings also highlight the shortcomings in state provision of services for families, and the repercussions this has on their QoL (Giné et al. 2006; Brown et al. 2011). Regarding the relationship between demographics and FQoL, our results show a relationship between FQoL and level of income and education. This finding is in line with other studies in FQoL in other countries (Wang et al. 2004; Lin et al. 2009; $\mathrm{Hu}$ et al. 2012), which have found that families with a family member with intellectual disability have lower QoL when their income and education levels are lower. This suggests that there is a need to offer support to people and families, particularly those with lower income and educational levels. Employment also seems to be an important aspect in relation to FQoL. Vilaseca et al. (2014) found that employed mothers reported better positive perceptions and lower levels of anxiety and depression than mothers in part-time employment or unemployed. So, the present authors think that encouraging parents 
to work outside the home, especially mothers, may be a way of raising FQoL. As regards FQoL and individual characteristics of family members with intellectual disability, the present authors found that family members with intellectual disability with more severe disabilities reported better FQOL. This may appear surprising, and indeed, other studies have found relationships in the opposite direction; that is, that people with intellectual disability with less severe disabilities report higher FQoL (Chiu et al. 2013a,b), or no relationship between severity of disability and FQoL (Córdoba et al. 2008; Lin et al. 2009). In our sample, the group with severe disabilities was the one that presented highest QoL (41.53\%) and included individuals with intellectual disability between 2 and 70 years of age. Possibly, people with more severe impairment in Catalonia receive more support than others with less evident needs; therefore, in families with a member with less severe impairment, the insufficient support provided may have repercussions for the family unit as a whole and may be reflected in the FQoL. More studies that explore relationships between degree of disability and FQoL are needed to develop better intervention and supports.

With regard to the third objective, the results show that the services that people with intellectual disability need most are health services, leisure services, personal assistance and psychological support. These results corroborate those of other studies conducted in other countries which have stressed the need for health services especially with people with more severe disabilities (Redmond \& Rishardson 2003), leisure and social inclusion services (Llewellyn et al. 1998) and emotional support (Epley et al. 2011). With regard to determining families' perceptions of whether their family member with intellectual disability receives the services he/she needs, our results show that the family member with intellectual disability receives fewer services than are needed. This highlights the importance of ascertaining individuals' needs in order to review the services being offered and to determine whether the problem is a lack of provision, the provision of the wrong kind of services, or services not being received often enough. It should be borne in mind that the needs of individuals and their families (and therefore their need for support) change over time, and a service that was appropriate at a given age may not be so at another time in life (Dunst \& Deal 1994). The different services that the state provides for people with intellectual disability and their families need to take this into account so that they can be matched to needs at any given point in time (Brown et al. 2003). Whatever the case, our results confirm the findings of other studies, namely that people with intellectual disability have needs that are not being met (Granlund \& RollPettersson 2001; McLennan et al. 2008; Koch \& Mayes 2012).

Among the areas in which support is clearly not being provided in sufficient quantities are speech and language services (deemed insufficient by $78.74 \%$ of respondents) and support for alternative and augmentative communication systems (deemed insufficient by $77.32 \%$ of respondents). These results confirm the findings of other studies regarding the need among individuals with intellectual disability for support in language and communication (Summers et al. 2007). Support for adapting the home and technical assistance for visual and auditory disabilities are other services which families consider to be insufficient. Other support needs still not satisfactorily addressed, but which some families (between 30 and 46\%) perceive to be covered sufficiently, are help in inclusive school, homecare, behavioural support at home, physical therapy and psychomotor services, support for access to education, leisure, and job placement services and professional coordination of services. Our results in this regard do not differ greatly from those of other studies (Granlund \& Roll-Pettersson 2001; Ellis et al. 2002; Summers et al. 2007; McLennan et al. 2008). In relation to the professional coordination of services, other studies (Freedman \& Capobianco 2000; Cassidy et al. 2008; Kogan et al. 2008; Burton-Smith et al. 2009) found that this service was one of the most frequently requested supports and was one that helped families the most to deal with their disabled member. Therefore, this is one of the aspects to bear in mind, especially when the person with intellectual disability changes from one service to another (e.g. from the Early Intervention Centre to school, or from school to the workplace).

As regards the examination of the services needed by the family (parents, siblings, other relatives and also the person with intellectual disability), our results show that the ones most needed in Catalonia are to do with informational resources and financial resources, followed by emotional resources. These results are in agreement with those reported in studies in other countries (Bailey \& Simeonsson 1988; Turnbull et al. 2006; Summers et al. 2007; Hsu \& Lin 2008; BurtonSmith et al. 2009; Palisano et al. 2010; Ahmadi et al. 2011; Almasri et al. 2012; Samuel et al. 2012; Chiu et al. 2013a, b; Zuna et al. in press). 
Regarding the degree to which the families of the individual with intellectual disability receive the services they need, the situation would seem to be particularly negative. Many of the families surveyed believe that the support they receive is extremely low given their needs, especially in areas such as respite care, household support, counselling or support groups for parents and siblings. These results are similar to those found by Ellis et al. (2002), Epley et al. (2011), Quine \& Pahl (1989), Samuel et al. (2012), Sloper \& Turner (1992), Sloper (1999) and Zuna et al. (in press). Another type of support that families consider to be insufficient is financial support. Other studies have found similar results, such as Brown et al. (2011), Palisano et al. (2010) and Samuel et al. (2012), and in fact, this is one of the variables that have the greatest influence on FQoL. Informational support, both general and about specific disabilities, or for planning for the family member's future, appears to be the type of support that is supplied the least. Our results also suggest that this type of support is the kind most requested by parents - as it is in other countries where different policies are in place. Good access to information regarding both their family member with intellectual disability and the family as a whole may increase their sense of control and of being capable and autonomous enough to act appropriately within the different contexts of life and thus help to improve their FQoL (Knox et al. 2000). Obviously, certain families will have greater need of particular types of support than others, and so the results cannot be generalized to all families with family members with intellectual disability.

Advocating more assistance and support for families with a member with disability, as this study does, does not mean denying the support needs of individuals with intellectual disability. Rather, individual and familylevel needs and support related to them must interact to improve FQoL, and therefore, both sets of needs must be met. Research on the needs of families with a family member with disabilities indicates that these families need a great deal of support over the course of their life, either to adapt to or to cope with the experience of raising and/or caring for a person with intellectual disability. If the aim is to promote high FQoL, then families have to be provided with much more support than they currently receive, as the vast majority of individuals with intellectual disability in this study live in their family homes.

These findings have implications for the resources that are assigned to the attention of families in different countries, and in particular in Catalonia. In our view, it is necessary to consider not just the care given to people with intellectual disability, but new ways of working with families through policies developed specifically to address their needs - for example supporting them in their caregiving role by designing interventions based on the family's strengths, and following family-centred approaches (Dunst et al. 2009; Epley et al. 2010; McWilliam 2012). A new approach of this kind would help to empower families with a family member with disabilities and enable them to deal more effectively with the different contexts in which they live. The present authors are also convinced that this approach can help to improve the QoL of parents, siblings and other family members, as other studies have already highlighted (Folkman \& Moskowitz 2000; Trivette \& Dunst 2007; Kyzar et al. 2012; Chiu et al. 2013a,b; Cohen et al. 2013).

This research reports FQoL outcomes in a large sample of Spanish families with a family member with intellectual disability. The present authors hope that the results will also contribute to assessing the relationship between individual and family needs for support and FQoL. More research is needed to assess the variety of factors that interact with family needs and FQoL. Our findings indicate that families and people with intellectual disability require many types of services and support but do not receive them and that family support plans are clearly needed to achieve better outcomes in FQoL.

This study has some limitations. The first is its crosssectional design; longitudinal studies should be conducted to complement its findings. Another limitation, which seems to be common in this kind of research, is related to sample selection (Brown et al. 2003; Summers et al. 2005; Hoffman et al. 2006). Although the present authors aimed to obtain as representative a sample as possible, the responses nonetheless correspond solely to those families who were willing to participate. The sample was drawn from a large association which seeks to meet the needs of families with children with intellectual disability in Catalonia. A further potential weakness of the study is that the results are derived from the analysis of written questionnaires, a kind of instrument with an inherent set of limitations. Finally, the N\&S questionnaire was created ad hoc for the present research and had not been previously tested. Therefore, although the main indicators or reliability seem appropriate, the results obtained from the questionnaire should be treated with 
caution, especially until clearer indicators of construct validity are obtained. In future studies, it would be interesting to assess the construct validity properties of the questionnaire, to use it in other similar contexts, and to compare these data with semi-structured interviews which take into account the perspectives of different family members, including parents, siblings and other members of the family unit.

\section{Acknowledgments}

The authors would like to thank the Jaume Bofill Foundation, which commissioned a group of researchers to conduct a study to determine the needs of both families and individuals with intellectual disability that culminated in the publication of a previous research paper (Giné et al. 2011) and the preparation of the present paper. The authors would also like to thank DINCAT and FEAPS for their help and the various services and families that participated in this study.

\section{Correspondence}

Any correspondence should be directed to Rosa Vilaseca, Department of Developmental and Educational Psychology, University of Barcelona, Passeig de la Vall d'Hebron, 171. 08035, Barcelona, Spain (e-mail: rosavilaseca@ub.edu).

\section{References}

AAIDD-American Association on Intellectual and Developmental Disabilities (2010) Intellectual Disability. Definition, Classification and Systems of Support. American Association on Intellectual and Developmental Disabilities, Washington, DC.

AAMR-American Association on Mental Retardation (2002) Mental Retardation. Definition, Classification and Systems of Support. American Association on Mental Retardation, Washington, DC.

Ahmadi A., Sharifi E., Azizi Zalani H., Bolouk S. \& Amrai K. (2011) The needs of Iranian families of children with autism spectrum disorder, cross-cultural study. Procedia - Social and Behavioral Sciences 15, 321-326.

Almasri N., Palisano R. J., Dunst C., Chiarello L. A., O’Neil M. E. \& Polansky M. (2012) Profiles of family needs of children and youth with cerebral palsy. Child: Care, Health and Development 38, 798-806. doi:10.1111/j.1365-2214.2011.01331.x.

APPS Federation (2006) Guia de recursos $i$ serveis per a les families que tenen un membre amb discapacitat intellectual (Guide to Resources and Services for Families with an Intellectually Disabled Member). APPS Federation, Barcelona.
Bailey D. B. \& Simeonsson R. J. (1988) Assessing needs of families with handicapped infants. The Journal of Special Education 22, 117-127.

Balcells-Balcells A., Giné C., Guardia-Olmos J. \& Summers J. A. (2011) Family quality of life: adaptation to Spanish population of several family support questionnaires. Journal of Intellectual Disability Research 55, 1151-1163.

Baldwin S. \& Carlisle J. (1994) Social Support for Disabled Children and their Families: A Review of the Literature. HM Stationery Office, Edinburgh.

Beresford B. (1995) Expert Opinions: A National Survey of Parents Caring for a Severely Disabled Child, pp. 209-218. Policy Press, Bristol.

Brown I., Anand S., Alan Fung W. L., Isaacs B. \& Baum N. (2003) Family quality of life: Canadian results from an international study. Journal of Developmental and Physical Disabilities 15, 207-230.

Brown R. I., MacAdam-Crisp J., Wang M. \& Iarocci G. (2006a) Family quality of life when there is a child with a developmental disability. Journal of Policy and Practice in Intellectual Disabilities 3, 238-245.

Brown I., Brown R. I., Baum N. T., Isaacs B. J., Myerscough T., Neikrug S., Roth D., Shearer J. \& Wang M. (2006b) Family Quality of Life Survey (General Version). Surrey Place Centre, Toronto, ON, Canada.

Brown R., Hong K., Shearer J., Wang M. \& Wang S. (2011) Family quality of life in several countries: results and discussion of satisfaction in families where there is a child with a disability. In: Enhancing the Quality of Life of People with Intellectual Disabilities Social Indicators Research Series, Vol. 41, pp. 377-398. Springer, Netherlands.

Brown H. K., Ouellette-Kuntz H., Hunter D., Kelley E. \& Cobigo V. (2012) Unmet needs of families of school-aged children with an autism spectrum disorder. Journal of Applied Research in Intellectual Disabilities 25, 497-508.

Burton-Smith R., McVilly K. R., Yazbeck M., Parmenter T. R. \& Tsutsui T. (2009) Service and support needs of Australian carers supporting a family member with disability at home. Journal of Intellectual and Developmental Disability 34, 239-247.

Carbó-Carreté M., Guàrdia-Olmos J. \& Giné C. (2015) Psychometric properties of the spanish version of the Personal Outcomes Scale. International Journal of Clinical and Health Psychology 15, 236-252. DOI: 10.1016/j.ijchp.2015.04.002.

Carpenter B. (1997) Empowering parents: the use of the parent as researcher paradigm in early intervention. Journal of Child and Family Studies 6, 391-398.

Cassidy A., McConkey R., Truesdale-Kennedy M. \& Slevin E. (2008) Preschoolers with autism spectrum disorders: the impact on families and the supports available to them. Early Childhood Development and Care 178, 115-128.

Chiu C. Y., Turnbull A. P. \& Summers J. A. (2013a) What families need: validation of the family needs assessment for Taiwanese families of children with intellectual disability and developmental delay. Research and Practice for Persons with Severe Disabilities 38, 247-258. 
Chiu C., Kyzar K., Zuna N. I., Turnbull A. P., Summers J. A. \& Aya V. (2013b) Family quality of life. In: Oxford Handbook of Positive Psychology and Disability (ed. M. W. Wehmeyer), pp. 365-392. Oxford University Press, New York, NY.

Cohen S. R., Holloway S. D., Domínguez-Pareto I. \& Kuppermann M. (2013) Receiving or believing in family support? Contributors to the life quality of Latino and nonLatino families of children with intellectual disability. Journal of Intellectual Disability Research 58, 333-345.

Córdoba L., Gómez J. \& Verdugo M. A. (2008) Calidad de vida familiar en personas con discapacidad: un análisis comparativo (Family quality of life for people with disabilities: a comparative analysis). Universitas Psychologica 7, 369-383.

Dunst C. J. \& Deal A. G. (1994) A family-centred approach to developing individualized family support plans. In: Supporting and Strengthening Families: Methods, Strategies and Practice (eds C. J. Dunst, C. M. Trivette \& A. G. Deal), pp. 73-88. Brookline, Cambridge, MA.

Dunst C. J. \& Trivette C. M. (2009) Using research evidence to inform and evaluate early childhood intervention practices. Topics in Early Childhood Special Education 29, 40-52.

Dunst C. J., Trivette C. M. \& Deal A. G. (eds.) (2009) Supporting and Strengthening Families: Methods, Strategies and Practice. Brookline Books, Cambridge.

Ellis T. J., Luiselli K. J. \& Amirault D. (2002) Families of children with developmental disabilities. Journal of Developmental and Physical Disabilities 2, 191-202.

Epley P., Summers J. A. \& Turnbull A. (2010) Characteristics and trends in family-centred conceptualizations. Journal of Family Social Work 13, 269-285.

Epley P., Summers J. A. \& Turnbull A. P. (2011) Family outcomes of early intervention: families' perceptions of need, services, and outcomes. Journal of Early Intervention 33, 201219.

Eskow K., Pineles L. \& Summers J. A. (2011) Exploring the effect of autism waiver services on family outcomes. Journal of Policy and Practice in Intellectual Disabilities 8, 28-35.

Folkman S. \& Moskowitz J. T. (2000) Stress, positive emotion, and coping. Current Directions in Psychological Science 9, 115118.

Freedman R. I. \& Capobianco N. (2000) The power to choose: supports for families caring for individuals with developmental disabilities. Health and Social Work 25, 59-68.

Giné C., Gràcia M., Vilaseca R. \& García-Díe M. T. (2006) Repensar la atención temprana: Propuestas para un desarrollo futuro. (Rethinking early childhood intervention: proposals for future development). Infancia y aprendizaje 29, 297-313.

Giné C., Balcells-Balcells A., Simó-Pinatella D., Font J., Pro T., Mas J. \& Carbó M. S. (2011) Necesidades de apoyo de las familias de personas con discapacidad intelectual de Catalunya (Support needs of families of people with intellectual disabilities in Catalonia). Siglo Cero: Revista Española sobre Discapacidad Intelectual, ISSN 0210-1696, 42, 31-49.
Giné C., Vilaseca R., Gràcia M., Mora J., Orcasitas J. R., Simón C., Torrecillas A. M., Beltran F. S., Dalmau M., Pro M. T., Balcells-Balcells A., Mas J. M., Adam-Alcocer A. L. \& SimóPinatella D. (2013) Spanish family quality of life scales: under and over 18 years old. Journal of Intellectual and Developmental Disability 38, 141-148.

Giné C., Gràcia M., Vilaseca R., Beltran F. S., Balcells-Balcells A., Dalmau M., Adam-Alcocer A. L., Pro T., Simó-Pinatella D. \& Mas J. (in press) Family quality of life of people with intellectual disability in Catalonia. Journal of Policy and Practice in Intellectual Disabilities.

Gómez L. E., Verdugo M. A., Arias B., Rodríguez A. \& Navas P. (2010) Calibrating the GENCAT scale: an instrument for assessing QoL in social service recipients. Journal of Applied Research in Intellectual Disabilities 23, 531.

Gómez L. E., Verdugo M. A., Arias B. \& Arias V. B. (2011) A comparison of alternative models of individual quality of life for social service recipients. Social Indicators Research 101, 109 126.

Gómez L. E., Verdugo M. A. \& Arias B. (2015) Validity and reliability of the INICO-FEAPS Scale: an assessment of quality of life for people with intellectual and developmental disabilities. Research in Developmental Disabilities 36, 600-610.

Granlund M. \& Roll-Pettersson L. (2001) The perceived needs of support of parents and classroom teachers: a comparison of needs in two microsystems. European Journal of Special Needs Education 16, 225-244.

Hastings R. P. (2003) Child behaviour problems and partner mental health as correlates of stress in mothers and fathers of children with autism. Journal of Intellectual Disability Research 47, 231-237.

Hoffman L., Marquis J., Poston D., Summers J. A. \& Turnbull A. (2006) Assessing family outcomes: psychometric evaluation of the beach centre family quality of life scale. Journal of Marriage and Family 68, 1069-1083.

Hsu S. \& Lin P. (2008) The study of family stress events and family support service needs. Providence Studies on Humanities and Social Sciences 2, 1-26.

Hu X., Wang M. \& Fei X. (2012) Family quality of life of Chinese families of children with intellectual disabilities. Journal of Intellectual Disability Research 56, 30-44.

Knox M., Parmenter T. R., Atkinson N. \& Yazbeck M. (2000) Family control: the views of families who have a child with an intellectual disability. Journal of Applied Research in Intellectual Disabilities 13, 17-28.

Kober R. (ed.) (2010) Enhancing the Quality of Life of People with Intellectual Disabilities. From Theory to Practice. Springer, New York.

Koch C. \& Mayes R. (2012) The balancing act: meeting the needs of all children including an adolescent with disabilities. Journal of Applied Research in Intellectual Disabilities 25, 464475.

Kogan M. D., Strickland B. B., Blumberg S. J., Singh G. K., Perrin J. M. \& Van Dyck P. C. (2008) A national profile of the health care experiences and family impact of autism 
spectrum disorder among children in the United States, 20052006. Pediatrics 122, e1149-e1158.

Kyzar K. B., Turnbull A. P., Summers J. A. \& Gómez V. A. (2012) The relationship of family support to family outcomes: a synthesis of key findings from research on severe disability. Research and Practice for Persons with Severe Disabilities 37, 31-44.

Lin J. D., Hu J., Yen C. F., Hsu S. W., Lin L. P., Loh C. H., Chen M. H., Wu S. R., Chu C. M. \& Wu J. L. (2009) Quality of life in caregivers of children and adolescents with intellectual disabilities: use of WHOQOL-BREF survey. Research in Developmental Disabilities 30, 1448-1458.

Llewellyn G., McConnell D. \& Bye R. (1998) Perception of service needs by parents with intellectual disability, their significant others and their service workers. Research in Developmental Disabilities 19, 245-260.

Luckasson R. \& Schalock R. L. (2013) Defining and applying a functionality approach to intellectual disability. Journal of Intellectual Disability Research 57, 657-668.

Luckasson R., Coulte D. L., Polloway E. A., Reiss S., Schalock R. L., Snell M. E., Spitalnik D. M. \& Satrk J. A. (1992) Mental Retardation: Definition, Classification, and systems of supports. D.C., Autor, Washington.

Luckasson R., Borthwick-Duffy S., Buntix W. H., Coultre D. L., Craig E. M., Reeve A., Schalock R. L., Snell M. E., Spitalnik D. M., Spreat S. \& Tassé M. J. (2002) Mental Retardation: Definition, Classification, and Systems of Supports, 10th edn. American Association on Mental Retardation, Washington, DC.

McLennan J. D., Huculak S. \& Sheehan D. (2008) Brief report: Pilot investigation of service receipt by young children with autistic spectrum disorders. Journal of Autism and Developmental Disorders 38, 1192-1196.

McWilliam R. (2012) Implementing and preparing for home visits. Topics in Early Childhood Special Education 31, 224-231.

Palisano R. J., Almarsi N., Chiarello L. A., Orlin M. N., Bagley A. \& Maggs J. (2010) Family needs of parents of children and youth with cerebral palsy. Child: Care Health, and Development 36, 85-92.

Plant K. M. \& Sanders M. R. (2007) Predictors of care-giver stress in families of preschool-aged children with developmental disabilities. Journal of Intellectual Disability Research 51, 109-124.

Quine L. \& Pahl J. (1989) Stress and Coping in Families Caring for a Child with Severe Mental Handicap: A Longitudinal Study. University of Kent, Canterbury, UK.

Redmond B. \& Rishardson V. (2003) Just getting on with it: exploring the service needs of mothers who care for young children with severe/profound and life-threatening intellectual disability. Journal of Applied Research in Intellectual Disabilities 16, 205-218.

Samuel P. S., Hobden K. L., LeRoy B. W. \& Lacey K. K. (2012) Analysing family service needs of typically underserved families in the USA. Journal of Intellectual Disability Research 56, 111-128.

Schalock R. L., Borthwick-Duffy S. A., Bradley V. J., Buntix W. H. E., Coulter D. L. \& Craig E. M. et al. (2010) Intellectual
Disability, Definition, Classification and Systems of Supports, 11th edn. American Association on Intellectual and Developmental Disabilities, Washington, DC.

Sloper P. (1999) Models of service support for parents of disabled children. What do we know? What do we need to know?. Child: Care, Health and Development 25, 85-99.

Sloper P. \& Turner S. (1992) Service needs of families of children with severe physical disability. Child: Care, Health and Development 18, 259-282.

Summers J. A., Poston D. J., Turnbull A. P., Marquis L., Hoffman L., Mannan H. \& Wang M. (2005) Conceptualizing and measuring family quality of life. Journal of Intellectual Disability Research 49, 777-783.

Summers J. A., Marquis J., Mannan H., Turnbull A. P., Fleming K., Poston D. J., Wang M. \& Kupzyk K. (2007) Relationship of perceived adequacy of services, family-professional partnerships, and family quality of life in early childhood service programmes. International Journal of Disability, Development and Education 54, 319-338.

Trivette C. M. \& Dunst C. J. (2007) Capacity-building familycentred help giving practices. Winterberry Research Reports 1, $1-10$.

Turnbull A. \& Turnbull R. (1990) A tale about lifestyle change: comments on toward a technology of "nonaversive" behavioral support. Journal of the Association for Persons with Severe Handicaps 15, 142-144.

Turnbull A. P., Turnbull H. R., Erwin E. \& Soodak L. (2006) Families, Professionals and Exceptionality. Positive Outcomes Though Partnership and Trust, 5th edn. Merrill/Prentice Hall, Upper Saddle River.

Turnbull A. P., Summers J. A., Lee S. H. \& Kyzar K. (2007) Conceptualization and measurement of family outcomes associated with families of individuals with intellectual disabilities. Mental Retardation and Developmental Disabilities Research Reviews 13, 346-56.

Van Loon J., Van Hove G., Schalock R. L. \& Claes C. (2009) Personal Outcomes Scale. Administration and Standardization Manual. Stichting Arduin and Gent, Belgium. University of Gent, Belgium, Middelburg, The Netherlands.

Verdugo M. A., Arias B., Gómez L. E. \& Schalock R. L. (2009) Formulario de la Escala GENCAT de Calidad de Vida. Manual de aplicación de la Escala GENCAT de Calidad de Vida (GENCAT Quality of life Scale. Application Manual). Departamento de Acción Social y Ciudadanía. Generalitat de Catalunya, Barcelona.

Verdugo M. A., Gómez L. E., Arias B. \& Schalock R. L. (2010a) The integral quality of life scale: development, validation and use. In: Enhancing the Quality of Life of People with Intellectual Disabilities (ed. R. Kober), pp. 47-60. Springer, Amsterdam, The Netherlands. doi: 10.1007/978-90-481-9650-0_4.

Verdugo M. A., Arias B., Ibáñez A. \& Schalock R. L. (2010b) Development of an objective instrument to assess quality of life in social services: reliability and validity in Spain. International Journal of Clinical and Health Psychology 10, 105-123. 
Verdugo M. A., Gómez L. E., Arias B., Santamaria M., Clavero D. \& Tamarit J. (2013) Escala INICO-FEAPS: Evaluación Integral de la Calidad de Vida de Personas con Discapacidad Intelectual $o$ del Desarrollo (INICO-scale FEAPS: Comprehensive Assessment of the Quality of Life of Persons with Intellectual Disability and Development). INICO, Salamanca.

Verdugo M. A., Gómez L. E., Arias B., Navas P. \& Schalock R. L. (2014) Measuring quality of life in people with intellectual and multiple disabilities: validation of the San Martin Scale. Research in Developmental Disabilities 35, 75-86.

Vilaseca R., Ferrer F. \& Guardia J. (2014) Gender differences in positive perceptions, anxiety, and depression among mothers and fathers of children with intellectual disabilities: a logistic regression analysis. Quality \& Quantity 48, 2241-2253. doi:10.1007/s11135-013-9889-2.
Wang M., Mannan H., Poston D., Turnbull A. P. \& Summers J. A. (2004) Parents' perceptions of advocacy activities and their impact on family quality of life. Research $\mathcal{E}$ Practice for Persons with Severe Disabilities 29, 144-155.

Zuna N. I., Turnbull A. \& Summers J. A. (2009) Family quality of life: moving from measurement to application. Journal of Policy and Practice in Intellectual Disabilities 6, 25-31.

Zuna N., Summers J. A., Turnbull A. P., Hu X. \& Xu S. (2010) Theorizing about family quality of life. In: Enhancing the Quality of Life of People with Intellectual Disability: From Theory to Practice (ed. R. Kober), pp. 241-78. Springer, Dordrecht.

Zuna N., Gràcia M., Haring S. H. \& Aguilar J. M. (in press) Parental perceptions and satisfaction with family services in families of children with autism and other developmental disabilities.. Journal of Intellectual \& Developmental Disability. 